AperTO - Archivio Istituzionale Open Access dell'Università di Torino

\title{
Concerns about change and employee wellbeing: the moderating role of social support
}

\section{This is the author's manuscript}

Original Citation:

Availability:

This version is available http://hdl.handle.net/2318/1661802

since 2020-04-23T10:56:31Z

Published version:

DOI:10.1108/JWL-09-2017-0083

Terms of use:

Open Access

Anyone can freely access the full text of works made available as "Open Access". Works made available under a Creative Commons license can be used according to the terms and conditions of said license. Use of all other works requires consent of the right holder (author or publisher) if not exempted from copyright protection by the applicable law. 


\section{Concerns about change and employee wellbeing: the moderating role of social support}

\begin{tabular}{|r|l|}
\hline Journal: & Journal of Workplace Learning \\
\hline Manuscript ID & JWL-09-2017-0083.R1 \\
\hline Manuscript Type: & Research Paper \\
\hline Keywords: & Concerns about change, Social support, Burnout, Work engagement \\
\hline
\end{tabular}

SCHOLARONE ${ }^{\text {M }}$

Manuscripts 


\section{Concerns about change and employee wellbeing: the moderating role of social support}

\section{Introduction}

Within the contemporary organizational change literature one of the topic of interest, which focuses on personal employees' attitudes and reactions to change (e.g. Elias, 2009; Vakola and Nikolau, 2005; Wanberg and Banas, 2006), has highlighted the stressful nature of organizational change and the factors underpinning for change success. Moreover, Isabella (1990), highlighted that the cognitive responses to the organizational change (perception about workload, autonomy, uncertainty, quality of communication ecc.) evolve through a series of stages, labeled anticipation, confirmation, culmination and aftermath.

Most of the studies, mainly conducted in the public - administrative and health - sectors, that have explored organizational change characteristics (e.g. downsizing, merges, restructuring or organizational re-design) and their consequences for employee' wellbeing, were conducted during the implementation and aftermath phases, highlighting increase in workload, role ambiguity, role conflict and job insecurity. These job demands are related, in turn, with negative attitudes toward change and impairments in physical and psychological health (Rafferty and Griffin, 2006; Day, et al., 2017; Kivimäki et al., 2000; Lavoie-Tremblay et al., 2010; Vakola and Nikolau, 2005).

At the same time, the decrease in job resources has also been highlighted. Dubois et al. (2014) confirmed how, in a longitudinal way, perceived autonomy, opportunity for stimulating work, group cohesion, and informal power decrease during such times. Moreover, Smollan (2015) showed, in a qualitative study, that higher workload and psychological demands, together with higher uncertainty and loss of social support from supervisors and colleagues, are perceived especially before and during the early stages of the change.

Given these stressful features, organizational change is highly correlated with a sense of uncertainty which may lead to a lessened sense of control over events, and, in turn, to more psychological 
discomfort, intention to leave the organization, and job dissatisfaction (Bordia et al., 2004; Paulsen et al., 2005; Rafferty \& Griffin, 2006). As evidenced from Pollard (2001), uncertainty reaches the highest levels during the anticipation stage of an organizational change, relating to an increase in cardiovascular diseases, psychological health problems, and arousal of tension.

As emerged from the above literature, the stressor-strain relationship has been widely studied during the implementation and aftermath change phases, while only a few studies have been conducted during the anticipation stage (Pollard, 2001; Paulsen et al., 2005), which represents the more stressful and uncertain phase for employees. During this period employees are informed about the incoming change, but often little in the way of specific information is formally communicated by the management.

In order to overcome this literature gap, data of the present study were collected during the anticipation stage of a broad reorganizational process within a public administrative sector, with the aim to analyze the role that is played by the emergence of concerns about change (Battistelli et al., 2014) which are a form of negative change-related evaluation that, for the most part, the literature has neglected.

Concerns about change are rooted within the Lazarus and Folkman's (1984) transactional stress theory, consisting of an appraisal in the face of the stressful and potentially threatening situations that will be derive from the change process. Specifically, individuals are supposed to appraise whether the change could be threatening or could have negative consequences for oneself (primary appraisal) and to evaluate whether they can cope with the stressful situation and fulfill the requirements of the change (secondary appraisal).

Concerns about change are conceptualized as an anticipation of future loss or threat, specifically determined by the incoming change (Battistelli et al., 2014). As the actual or anticipated loss of significant resources has primacy in the process leading to stress and burnout and to impairment of 
work engagement (Gorgievski and Hobfoll, 2008), we intend to examine how individuals appraise organizational change, and its consequences for psychological wellbeing, before its implementation. In light of these results, organizations that are planning for organizational changes, will be better informed about employees' early difficulties in facing the change.

Moreover, if concerns about change could harm employee wellbeing, we intend to analyze the protective role exerted from job resources (Bakker et al., 2005). In this vein, this study extends past research that focused on the key role played by social support in sustaining positive organizational change evaluations (Fuchs and Prouska, 2014) and in buffering change-related stressors (van Emmerik et a., 2009; Day et al., 2017).

Therefore, this study examine whether and how the concerns about change have an impact on burnout and work engagement levels and, in order to show how organizations should actively manage individual reactions to change, it will be evaluated the moderating role of social support, namely supervisor and co-worker support, between concerns and employee wellbeing outcomes.

\section{Theoretical Background}

\subsection{Conceptualizing concerns about change}

Differently from other change-related attitudes, such as openness (Wanberg and Banas, 2000), resistance (Oreg, 2006) or commitment to change (Herscovitch and Meyer, 2002), concerns about change refer to the appraisal process of the changing organizational context. Extending Lazarus and Folkman's transactional stress theory (1984), the way through which employees evaluate the organizational change could lead to developing a state of stress and, more generally, to a failure in the person-environment fit process. Specifically, this appraisal process implies an anticipation of resource losses due to the potentially negative consequences (primary appraisal). Moreover, the evaluation about one's own "capability" to face those consequences (secondary appraisal) may be affected as well. 
In order to identify this evaluative component, the conceptualization (Battistelli et al., 2014) includes three specific sub-dimensions: concerns about the content of change (CONT), concerns about the benefit of change (BEN), and concerns about mastering (MAST) change. Whereas the first (CONT) captures feelings of worries about the consequences of the ongoing change on one's role, the second (BEN) takes into account worries about whether the change will bring benefits for the individual or the organization. These two dimensions constitute the affective component of the appraisal process, reflecting how the employee perceives the change as potentially threatening (primary appraisal). The last dimension (MAST) concerns the cognitive component. This is an evaluation about one's own capability to successfully face the requirement derived from the change process, such as dealing with new tasks or using new work tools (secondary appraisal).

As showed from Battistelli et al. (2014), concerns about change represent a potential barrier to successful change implementation, as they are negatively related to commitment to change. Otherwise, no studies have highlight if these anticipatory stress reactions could impair also employees' psychological wellbeing before change implementation.

\subsection{Work engagement, burnout, and organizational change}

Work engagement and burnout rarely have been investigated in relationship with organizational change perceptions. Most studies have been focused on organizational, or on general mental health, consequences.

The core dimension of Burnout is emotional exhaustion (Loera et al., 2014; Maslach and Jackson, 1981), which refers to feelings of being depleted of emotional resources. Cynicism refers to negative and detached attitudes toward the job, underlying withdrawal behaviors from the excessive stressful situations. 
Dubois et al. (2014) observed, during the study period involving a reorganizational process, a significant decrease in job resources, which significantly predicted an increase in emotional exhaustion twelve months apart.

Work engagement, in contrast, is a positive state of mind characterized by vigor, dedication, and absorption (Schaufeli et al., 2002). Only recently this aspect has been taken into account in empirical research on organizational change (van den Heuvel et al., 2017). The authors followed the distinction between "change antecedents" and "pre-change antecedents" proposed by Oreg et al. (2011). On the one hand change antecedents include variables related to the change process, such as the quality of the communication or the perceived advantages or disadvantages resulting from change. On the other hand pre-change antecedents include change recipient characteristics and internal context variables that existed prior to the introduction of the change. van den Heuvel et al. (2017), conceptualizing work engagement as a "pre-change" antecedent, have pointed out that this positive state of mind mediates the relationship between a change antecedent (change information) and resistance to change.

Following Oreg et al. (2011), we evaluate concerns about change as a "change antecedent," which could be conceptualized as an anticipation of resource loss. Extending what has been highlighted by Dubois et al. (2014) and van den Heuvel et al. (2017), we formulate the following hypothesis:

H1: Concerns about the content, the benefit, and the ability for mastering change, will be negatively associated with work engagement and positively associated with cynicism and emotional exhaustion.

\subsection{The role of social support during organizational change}

The roles of sources of support experienced within the working context have been widely explored as powerful resources to overcome burnout symptoms or to strengthen work engagement and job 
satisfaction (e.g., Afsar and Badir, 2017; Cortini, 2016; Guglielmetti et al., 2014; Loera et al., 2013).

Within the change-related literature, some studies have examined the role of support from supervisors in sustaining a more positive attitude toward change and psychological wellbeing during organizational change (Fuchs and Prouska, 2014; Martin et al., 2005; Neves, 2011; Rafferty and Griffin, 2006; Swanson and Power, 2001). Moreover, support from colleagues was directly associated with more positive feedback (Swanson and Power, 2001) and to a more positive change evaluation (Fuchs and Prouska, 2014) during the aftermath phase.

Furthermore, research on social support has mostly focused on the buffering hypothesis, which describes the moderating role exerted by resources in the relationship between stressors and strains (e.g Bakker et al., 2005). Within the change-related literature, van Emmerik et al. (2009), showed that supervisor support significantly moderated the negative relationship between the emotional demands and favorable evaluations of organizational change. In a similar vein, Day et al. (2017) highlighted how supervisor support moderated the relationship between change-related stressors with both emotional exhaustion and cynicism.

Extending the above research stream, we intent to investigate the role of both supervisor and coworker support as a buffer against the negative effect of concerns about change on employee wellbeing. We hypothesize that:

H2: Support from colleagues and from the supervisor moderate the relationship between concerns about change and the outcome variables. That is to say, the positive relationship between concerns about change and both cynicism and emotional exhaustion will be stronger during conditions of low resources and weaker in conditions of high resources. The negative relationship between concerns about change and work engagement will be weaker in conditions of high resources and stronger in conditions of low resources. 


\section{Method}

\subsection{Background and Data Collection}

Data were collected during November 2016 and January 2017 in a research program aimed at assessing working life quality within a large public educational institution in the North of Italy. Data used in the present study were collected within the administrative sector of this organization before undergoing a macro-level structural reorganizational process. The main aim of that reorganizational process, was to identify a new organizational model that overcomes the distinction between peripheral and central work structures. Consequently, at the macro-level, the management decided to redefine the organogram, merging diverse functional sectors, rationalizing and reducing work processes, thus favoring cost-containment. However, no layoffs or downsizing were scheduled.

At the micro-level, the changes involved new roles, work tasks, colleagues, and superiors as a consequence of the implementation of new units' worksites. At the time of the data collection, employees were generically informed about the reorganizational process and its aims, which would have been formally and gradually implemented during subsequent months in 2017 . Moreover, HR management, during such times, was conducting interviews with the aim to screening suitable employees for new jobs' positions that would have been introduced by the re-organizational process. Nevertheless, employees did not know if they would have to change roles, positions, or worksite, or any of these.

Self-reported questionnaires were administered during working hours in a series of meetings organized by the research team of the Department of Psychology in conference rooms provided by the employer organization.

The voluntary nature of participation and the anonymity of the data collection were ensured. No treatment, including medical, invasive diagnostics, or procedures causing psychological or social 
discomfort, was administered to the participants. The research also conforms to the 1995 Declaration of Helsinki (as revised in Edinburgh in 2000).

\subsection{Participants}

At the time of the research, the administrative sector comprised 1854 employees. In total, 805 (43.41\%) employees took part in the meetings and returned the completed questionnaire. As 159 participants were not involved in the reorganizational process, they were excluded from the analysis. The final study sample included 632 employees, consisting of a majority of females $(72.5 \%)$. The mean age was 48.66 years $(\min =25 ; \max =65 ; \mathrm{DS}=7.73)$, the mean job tenure was 18.45 years $(\mathrm{DS}=9.34)$, and $601(95.1 \%)$ had a permanent contract.

\subsection{Measures}

Job and organizational resources: Support from colleagues (SC) (3 items, $\alpha=.90)$, e.g., "My colleagues are supportive in working difficulties") and Support from supervisor (SS) (3 items, $\alpha=$ .89, e.g., "My supervisor is supportive in working difficulties") were measured using the Organizational Support Scale (Range scale: 0 = Never; 3 = Always) (Caplan et al., 1975).

Concerns about change were measured using the scale proposed by Battistelli et al. (2014) aimed at assessing three independent sub-dimensions: Concerns about content of change (CONT) ( 3 items, $\alpha$ $=.74$, e.g. "I am concerned about the impact of this new change on my role"); concerns about benefit of change (BEN) (3 items, $\alpha=.81$; e.g., "I am concerned that I will get no personal benefit from this change); concerns about mastering change (MAST) (4 items, $\alpha=.76$; e.g., "I am concerned about not being really able to face new tasks"), (Range scale: $0=$ Totally disagree ; $3=$ Totally agree).

Outcomes. Regarding burnout, cynicism (CY) (5 items, $\alpha=.81)$ and emotional exhaustion (EE) (5 items, $\alpha=.85$ ), were taken into account based on subscales from the Maslach Burnout 
Inventory-General Survey (Schaufeli et al., 1996). Work engagement (WE) was measured through the 9-item Italian version of the Utrecht Work Engagement Scale (U-WES9) (Balducci et al., 2010), following author suggestions (Schaufeli et al., 2006; Balducci et al., 2010), to consider it as a unidimensional scale (9 items, $\alpha=.90$ ). Responses for both Burnout and Work Engagement measures were provided on a scale ranging from 0 ("Never") to 6 ("Every day").

Control variables: Gender and job tenure were included in the model as they could act as possible confounders in the relationship between perceived concerns and wellbeing at work. Moreover, as stated by previous studies (Rafferty and Griffin, 2006; Wanberg and Banas, 2000), also personal coping resources could impact on the perception of strain related to the change process. In this context, we inserted as a control variable Self-Efficacy (EFF), a measure of the efficacy in coping with obstacles at work, taken from the Italian Adaptation of General Self-Efficacy Scale (Falvo et al., 2002) (4 items, $\alpha=.70$; e.g., "If I can't do a job the first time, I keep trying until I can"), (Range scale: $0=$ Totally disagree $; 3=$ Totally agree).

\section{Data Analysis}

Data analyses were performed using SPSS Statistics 24.

Preliminary analyses included means, standard deviations, and Pearson's correlations between the study variables (Table 1). Moreover, assumption for regression analysis (Field, 2013), such as normally distributed errors (values of standard errors ranged from -2 and +2 ), and homoscedasticity (Cook distance $<1$ ), were assured for all models tested.

Moderated regression analyses were employed in order to examine the moderating effect of social support on the relationship between the three sub-dimensions of concerns about change and workrelated wellbeing outcomes. For all the moderated regression analyses, control variables were entered in the first step and the three dimensions of concerns about change in the second step. Moderators (either the SC and SS) were entered in the third step. Consistently with Aiken and West (1991), all involved variables were centered. Interaction terms were finally entered in the fourth 
step. In the cases in which the interaction term showed a significant value, the simple slope procedure recommended by Aiken and West (1991) was adopted to further examine the pattern of the relationship.

\section{Results}

As emerged from correlations (see Table 1), job resources and concerns about change correlated in the expected directions with all the outcome variables. CONT did not significantly correlate with WE. Consequently, we did not insert CONT in the regression models including WE as a dependent variable.

(Table 1 near here)

In Table 2 are reported moderated regression analyses assessing the direct effects of concerns about change on the outcome variables, and the buffering role of SC.

Regarding WE, no significant interactions were detected. Regarding EE, only BEN was positively and significantly associated, confirming H1. The interaction term explained a significant amount of variance $\left(\Delta \mathrm{R}^{2}=.013 ; \mathrm{p}=.047\right)$, highlighting a significant moderation only with $\operatorname{BEN}(\beta=-.139, \mathrm{p}$ $<.01)$. Slope test analyses were performed in order to further examine the direction of the effects of support from colleagues, in the relationship between BEN and EE. A simple slope analysis (Figure 1) showed that when this resource was high (+1 standard deviation, SD), the positive relationship between BEN and $\mathrm{EE}(t=2.36, p=.018)$ was weaker, albeit significant, if compared with a condition of low resource $(-1 \mathrm{SD}, t=-4.35, p=.001)$.

Finally, regarding CY, BEN and MAST were significantly and positively related to the outcome variable, whereas CONT was not significantly related to CY. These results confirmed H1. The interaction term explained a significant amount of variance in $\mathrm{CY}\left(\Delta \mathrm{R}^{2}=.016 ; \mathrm{p}=.014\right)$, highlighting a significant moderating effect only with $\operatorname{BEN}(\beta=-.162, \mathrm{p}=.001)$. A simple slope analysis (Figure 2) revealed that when SC was high (+1 Standard deviation, SD), the positive 
relationship between BEN and CY $(t=2.62, p=.009)$, albeit significant, was weaker if compared with a condition of low SC $(t=5.00, p=.000)$.

Finally, SS was significantly and positively associated with WE $(\beta=.110 ; p=.001)$ and negatively associated only with $\mathrm{CY}(\beta=-.412 ; \mathrm{p}=.000)$. When examining the moderating role of SS, the models including the interaction effects did not account for a significant difference of amount of variance explained either for EE or for CY. Regarding WE, interaction effects explained a significant amount of variance $\left(\Delta \mathrm{R}^{2}=.016 ; \mathrm{p}=0.03\right)$. Despite that, no significant interactions were detected. Moreover, we developed two distinct models testing the interaction effects of BEN and MAST independently. SS significantly buffered the relationship between MAST and WE, determining a significant amount of variance $\left(\Delta \mathrm{R}^{2}=.012 ; \mathrm{p}=0.03\right)$ (Table 3$)$.

A simple slope analysis (Figure 3) showed that when SS was high (+1 Standard deviation, SD) the negative relationship between MAST and WE was not significant $(t=-1.74, p=.081)$. Conversely, when SS was low $(+1$ Standard deviation, SD), WE steeply decreased at high levels of MAST $(t=$ $-3.51, p=.000)$

$\mathrm{H} 2$ was then partially confirmed as the moderating role exerted from SC was significant only for BEN in the relationship with emotional exhaustion and cynicism. Moreover, it emerged the moderating role of SS between MAST and WE.

(Table 2 near here)

(Table 3 near here)

\section{Discussion}

The general aim of this study was to increase the extant knowledge about the consequences of the organizational change process on employee wellbeing, adopting a micro-level approach. Within this perspective, this study makes an original contribution by examining an understudied reaction to 
organizational change, namely concerns about change evaluated during the anticipation stage, and which have been conceptualized as the anticipation of resource loss due to future organizational change implementation.

Firstly, it was explained how concerns about change were related to burnout symptoms and work engagement. Hierarchical regression analysis showed that BEN was significantly and positively associated with both EE and CY.

Worries about losses in benefit entail a dimension of reciprocity between the employees and the organization to which they belong and define a state of mind about expectancy between costs and benefits that will derive from the change process. In this vein, our study enlarges what was highlighted by the study of Dubois et al. (2014), which concluded that experiencing resource loss, such as a decrease in autonomy, in groups' cohesion, or in informal power due to an organizational change, significantly predicts emotional exhaustion and cynicism toward organizational change.

Moreover, our results shows that concerns about mastering change (MAST), which represents the evaluation of oneself as unable to successfully face new requirements given by the future implementation of a reorganizational change, is on one hand significantly related to the withdrawal component of burnout, namely CY. This results is consistent with Lazarus and Folkman's model of stress (1984): people tend to adopt avoidance strategies in the face of stressful situations that are evaluated as too demanding of their own resources. On the other hand, our results extend what has been previously shown from van den Heuvel et al. (2017), highlighting that MAST could act as a form of change antecedent (Oreg et al., 2011) relating to a decrease in WE. In this vein, it seems that experiencing an inability to face requirements due to change lessens the enthusiasm and the challenging vigor individuals tend to put into work. Moreover, this is of further importance if we consider the relevance that work engagement could have in contrasting resistance to change (van den Heuvel et al., 2017). 
Finally, contrarily to expectations, concerns about content of change (CONT), which refers to concerns about harmful consequences of organizational change on one's role, did not significantly explain the variance of any of the outcome variables. It is possible to state that, as the cognitive responses evolve through the change process (Isabella, 1991), CONT could be more salient in affecting employee wellbeing during subsequent phases of the change process. Moreover, as emerged from Battistelli et al. (2014), CONT could have a more prominent role in predicting other change-related attitudes, such as commitment to change, compared to wellbeing outcomes.

The second aim of our study was to analyze the buffering role of social support (Bakker et al. 2005) on the relationship between concerns about change and employee wellbeing.

The findings showed SC significantly buffered the relationship between BEN and both EE and CY. When BEN increased, employees with higher levels of SC reported less negative consequences (i.e., emotional exhaustion and cynicism), than did employees that experienced low levels of SC. It seems that having support from colleagues who are experiencing the same uncertainty situation could lead not only to improve the experience employees have with the change (Fuchs and Prouska, 2014;) but, as emerged from our study, to a perception of future resource loss as less threatening for the employees' wellbeing.

Moreover, this study highlights the relevance of SS in moderating the negative relationship between MAST and WE. The results showed that when SS was high, MAST did not exert any significant influence on WE levels. Conversely, low levels of SS significantly exacerbate the negative relationship between MAST and WE. Past research showed the relevance of a supportive supervisor during time of change implementation in improving positive change evaluation (Fuchs and Prouska, 2014), or in protecting from change-related stressors (Day et al., 2017; van den Heuvel et al., 2017). Our study goes beyond the extant literature. Specifically, receiving support from supervisors before change implementation could inform employees more effectively about their own ability to cope 
with possible difficulties and new tasks derived from the re-organizational process, thus favoring higher levels of work engagement.

In sum, the results obtained from the present study represent an essential development within the change-related literature.

Differently from other studies (e.g., Day et al., 2017; Dubois et al., 2014; van Emmerik et al., 2009), this research has switched the focus from the role exerted by change-related stressors, to one exerted by concerns about change during the anticipation stage of the change process.

Moreover, this study does not take into account the more widespread change-related constructs, such as commitment or resistance to change, but focused on employee wellbeing and disease. Even if concerns about change are informative about change success (Battistelli et al., 2014), the results of this study enlarge what have been shown from the seminal study of Battistelli et al (2014), highlighting that negative evaluations of the change process could harm employees' wellbeing, which in light of past studies could engender other negative outcomes, such as job dissatisfaction and intention to leave the organization (Dubois et al., 2014; Day et al., 2017). In this vein, future studies taking a longitudinal perspective, could inform about the mediating role exerted from burnout and work engagement in the relationship between concerns about change and other changerelated attitudes and outcomes.

On a practical level our research shows that organizations, when planning organizational change, should sustain employees' wellbeing through nurturing collaborative climate between co-workers (e.g. through Team building). In light of our results, poor co-worker support could indeed exacerbate the relationship between concerns about benefit of change and burnout. Moreover, sustaining co-worker support since the anticipation stage could prevent future harassment or violence behaviors that frequently arise from negative emotions favored by organizational change (De Vries and Balasz, 1997). 
In the same vein organizations could enhance the role of supervisors, which can be seen as key agents in the implementation of an organizational change (Neves, 2011), in promoting better communication and information about future changes regarding task and skills required to employees or increasing employees' participation in change initiatives.

The main limitations of this study are the cross-sectional nature and the presence of self-reported data. In this vein, longitudinal research could overcome on one hand the bias due to common method variance that affects this type of research design. Moreover, in order to infer causal relationships between variables, evaluating concerns about change over time could evidence if any variation is related to employees' wellbeing and other attitudes toward change, such as commitment to change. Moreover, future longitudinal studies could add more insights on these relationships, evaluating the mediating role of burnout and work engagement between concerns about change and the outcome variables.

A second limitation is that this study was drawn on a specific group of professionals within the administrative sector in an Italian public sector. Moreover, the sample was not randomized. These features do not permit to generalize the results to other working groups or occupations. Future research could indeed analyze this relatively new construct in other organizational changing environments.

\section{References}

Afsar, B. and Badir, Y. (2017), "Workplace spirituality, perceived organizational support and innovative work behavior: The mediating effects of person-organization fit", Journal of Workplace Learning, Vol. 29 No. 2, pp. 95-109.

Aiken, L. S. and West, S. G. (1991), Multiple regression: Testing and interpreting interactions, Thousand Oaks, CA: Sage Publications. 
Bakker, A.B., Demerouti, E. and Euwema, M.C. (2005), “Job resources buffer the impact of job demands on burnout", Journal of Occupational Health Psychology, Vol. 10 No. 2, pp. 170.

Balducci, C., Fraccaroli, F. and Schaufeli, W.B. (2010), "Psychometric Properties of the Italian Version of the Utrech Work Engagement Scale (UWES-9). A Cross-Cultural Analysis", European Journal of Psychological Assessment, Vol. 26 No. 2, pp. 143-149.

Battistelli, A., Montani, F., Odoardi, C., Vandenberghe, C. and Picci P. (2014), “Employees' concerns about change and commitment to change among Italian organizations: the moderating role of innovative work behavior", The International Journal of Human Resource Management, Vol. 25 No. 5, pp. 951-978.

Bordia, P., Hunt, E., Paulsen, N. and DiFonzo, N. (2004). "Uncertainty during organizational change: Is it all about control?", European Journal of Work and Organizational Psychology, Vol. 13 No. 3, pp. 345-365.

Caplan, R.D., Cobb, S., French, J.R.P. Jr., van Harrison, R. and Pinneau, S.R. Jr. (1975), Job demands and worker health, Washington, DC: National Institute if Occupational Safety and Health.

Cortini, M. (2016), “Workplace identity as a mediator in the relationship between learning climate and job satisfaction during apprenticeship", Journal of Workplace Learning, Vol. 28 No. 2, pp. 54-65.

Day, A., Crown, S.N. and Ivany, M. (2017), “Organizational change and employee burnout: the moderating effects of support and job control", Safety Science, in press.

De Vries, M.F.K. and K. Balazs (1997), “The Downside of Downsizing”, Human Relations, Vol. 50 No. 1, pp. 11-50.

Dubois, C.A., Bentein, K., Mansour, J.B., Gilbert, F. and Bedard, J.L. (2014), "Why some employees adopt or resist reorganization of work practices in health care: associations between perceived loss of resources, burnout, and attitudes to change", International Journal of Environmental Research and Public Health, Vol. 11 No. 1, pp. 187-201. 
Elias, S.M. (2009), "Employee commitment in times of change: assessing the importance of attitudes toward organizational change", Journal of Management, Vol. 35 No. 1, pp. 37-55.

Falvo, R., Hichy, Z., Capozza, D. and De Carlo, N.A. (2002), “Impegno nei confronti dell'azienda, percezione di autoefficacia personale e collettiva e comportamenti organizzativi”, Testing Psychometric Metrodologies in Applied Psychology (TPM), Vol. 9 No. 1-2, pp. 57-70.

Field, A. (2013), Discovering statistics using SPSS statistics: and sex and drugs and rock ' $n$ ' roll, 4th Edition, Los Angeles: SAGE publications.

Fuchs, S. and Prouska, R. (2014). "Creating positive employee wellbeing change evaluation: the role of different levels of organizational support and change participation (2014)", Journal of Change Management, Vol. 14 No. 3, pp. 361-383.

Gorgievski, M.J. and Hobfoll, S.E. (2008), Work can burn us out and fire us up. In J.R.B. Halbesleben (ed.), "Handbook of stress and burnout in health car"e, Hauppage, New York: Nova Publishers, pp. 7-22.

Guglielmetti, C., Gilardi, C., Accorsi, L. and Converso, D. (2014). La relazione con i pazienti in sanità: quali risorse lavorative per attenuare l'impatto degli stressor sociali? [The relationship with patients in healthcare: which workplace resources can lessen the impact of social stressor?]. Psicologia della Salute, Vol 2, pp. 121-137.

Herscovitch, L. and Meyer, J.P. (2002), “Commitment to Organizational Change: Extension of a Three-Component Model” Journal of Applied Psychology, Vol. 87 No. 3, pp. 474-487.

Isabella, L. (1990). "Evolving interpretations as a change unfolds: how managers construe key organizational events", Academy of Management Journal, Vol. 33 No 1, pp. 7-41.

Kivimäki, M., Vahtera, J., Pentti, J. and Ferrie, J.E (2000), "Factors underlying the effect of organisational downsizing on health of employees: longitudinal cohort study", British Medical Journal, Vol. 320 No. 8, pp. 971-975.

Lavoie-Tremblay, M., Bonin, J.P., Lesage, A.D., Bonneville-Roussy, A., Lavigne, G.L. and Laroche, D. (2010), “Contribution of the psychosocial work environment to psychological 
distress among health care professionals before and during a major organizational change", Health Care Manager Vol. 29 No. 4, pp. 293-304.

Lazarus, R.S., and Folkman, S. (1984), “Stress, Appraisal, and Coping”, New York: Springer.

Loera B., Converso D. and Viotti S. (2014). "Evaluating the Psychometric Properties of the Maslach Burnout Inventory-Human Services Survey (MBI-HSS) among Italian Nurses: How Many Factors Must a Researcher Consider?” PLoS ONE, Vol. 9, No. 12: e114987, pp. $1-18$.

Loera B., Gattino S. and Converso D. (2013) Giustizia organizzativa, supporto sociale e burnout tra lavoratori della Sanità: effetti diretti e di moderazione. Psicologia della Salute, Vol. 1, pp. $27-48$.

Martin, A.J., Jones, E.S. and Callan, V.J. (2005), “The role of psychological climate in facilitating employee adjustment during organizational change", European Journal of Work and Organizational Psychology, Vol. 14 No. 3, pp. 263-289.

Maslach, C. and Jackson, S.E. (1981), "The measurement of experienced burnout", Journal of Occupational Behavior, Vol. 2 No. 2, pp. 99-113.

Neves, P. (2009), “Readiness for Change: Contributions for Employee's Level of Individual Change and Turnover Intentions", Journal of Change Management, Vol. 9 No. 2, pp. 215231.

Oreg, S. (2006), "Personality, Context, and Resistance to Organizational Change" European Journal of Work and Organizational Psychology, Vol. 15 No. 1, pp. 73-101.

Oreg, S., Vakola, M., and Armenakis, A. (2011), “Change recipients' reactions to organizational change: a 60-year of review of quantitative studies”, Journal of Applied Behavioral Studies, Vol. 47 No. 4, pp. 461-524.

Paulsen, N., Callan, V.J.,. Grice, T.A., Rooney, D., Gallois, C., Jones, E., Jimmieson N.L., and Bordia P. (2005), “Job uncertainty and personal control during downsizing: A comparison of survivors and victims", Human relations, Vol. 58 No. 4, pp. 463-496 
Pollard, T.M. (2001), “Changes in mental well-being, blood pressure and total cholesterol levels during workplace reorganization: The impact of uncertainty", Work and Stress, Vol. 15 No. 1, pp. 14-28.

Rafferty, A.E. and Griffin, M.A. (2006), "Perceptions of organizational change: a stress and coping perspective”, Journal of Applied Psychology, Vol. 91 No. 5, pp. 1154-1164.

Schaufeli,W. B., Bakker, A. B., and Salanova, M. (2006), “The measurement of work engagement with a short questionnaire", Educational and Psychological Measurement, Vol. 66 No. 4, pp. 701-716.

Schaufeli, W.B., Leiter, M.P., Maslach, C. and Jackson, S.E. (1996), The MBI-General Survey, in Maslach, C., Jackson, S.E., Leiter, M.P. (eds.), “Maslach Burnout Inventory manual (3rd ed.)", Consulting Psychologists Press (1996).

Schaufeli, W.B., Salanova, M., González-Romá, V. and Bakker, A.B. (2002), “The measurement of engagement and burnout: A two sample confirmatory factor analytic approach”, Journal of Happiness Studies, Vol. 3 No. 1, pp. 71-92.

Smollan, R. K. (2015), "Causes of stress before, during and after organizational change: a qualitative study", Journal of Organizational Change Management, Vol. 28 No. 2, pp. 301314.

Swanson, V. and Power, K., (2001), “Employees' perception of organizational restructuring: the role of social support", Work and Stress, Vol. 15 No. 2, pp. 161-178.

Vakola, M. and Nikolaou, I. (2005), “Attitudes towards organizational change. What is the role of employees’ stress and commitment?”, Employee Relations Vol. 27 No. 2, pp. 160-174.

van den Heuvel, S., Freese, C., Schalk, R. and van Assen, M. (2017), "How change information influences attitudes toward change and turnover intention. The role of engagement, psychological contract fulfillment and trust", Leadership and Organization Development Journal, Vol. 38 No. 3, pp. 398-418. 
van Emmerik, I.J.H., Bakker A.B. and Euwema, M.C. (2009), “Explaining employees’ evaluations of organizational change with the job-demands resources model", Career Development International, Vol. 14 No. 6, pp. 594-613.

Wanberg, C.R., and Banas, J.T. (2000), "Predictors and Outcomes of Openness to Changes in a Reorganizing Workplace”, Journal of Applied Psychology, Vol. 85 No. 5, pp. 132-142. 


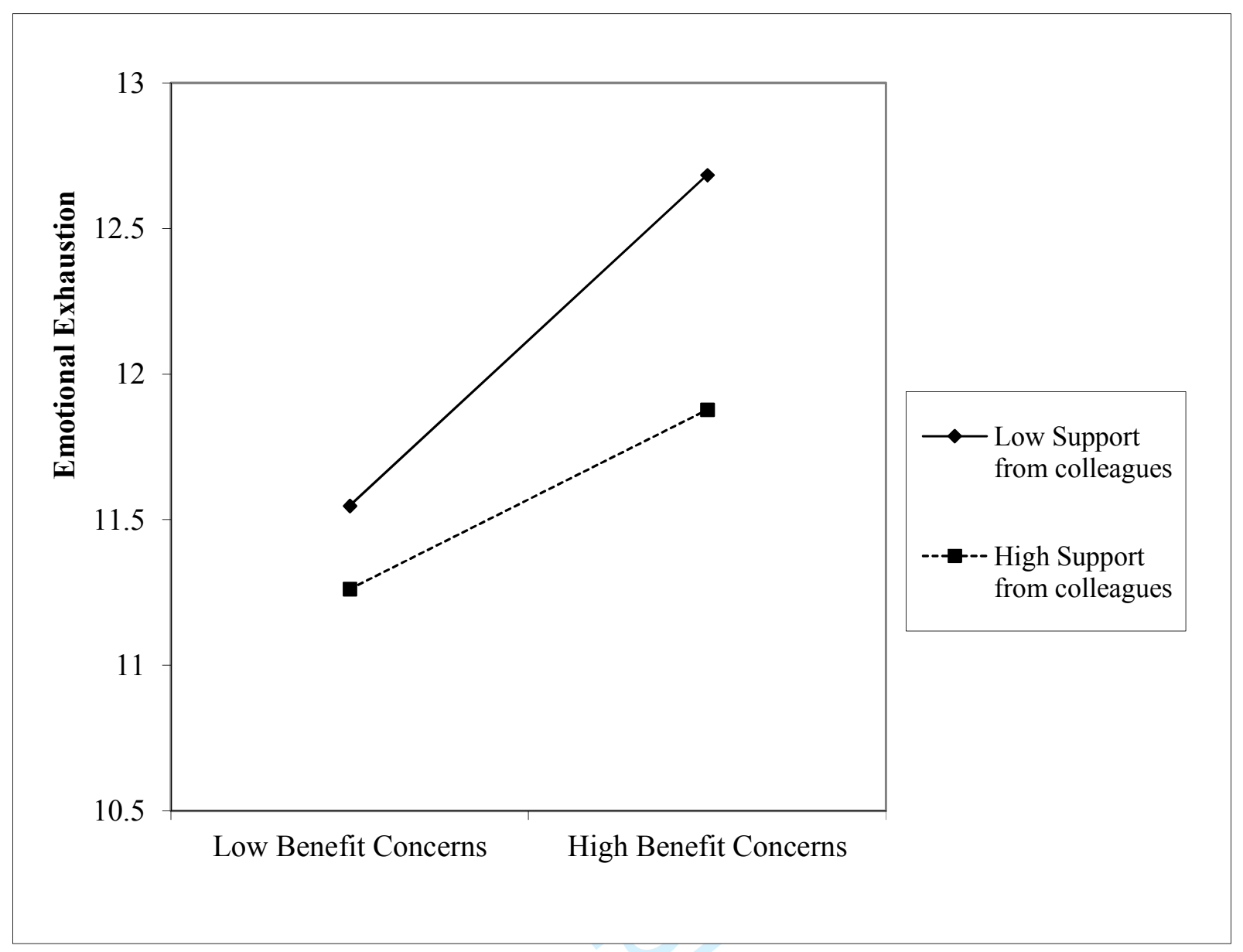

Figure 1. The moderating effect of support from colleagues (SC) in the relationship between benefit concerns (BEN) and Emotional Exhaustion (EE) 


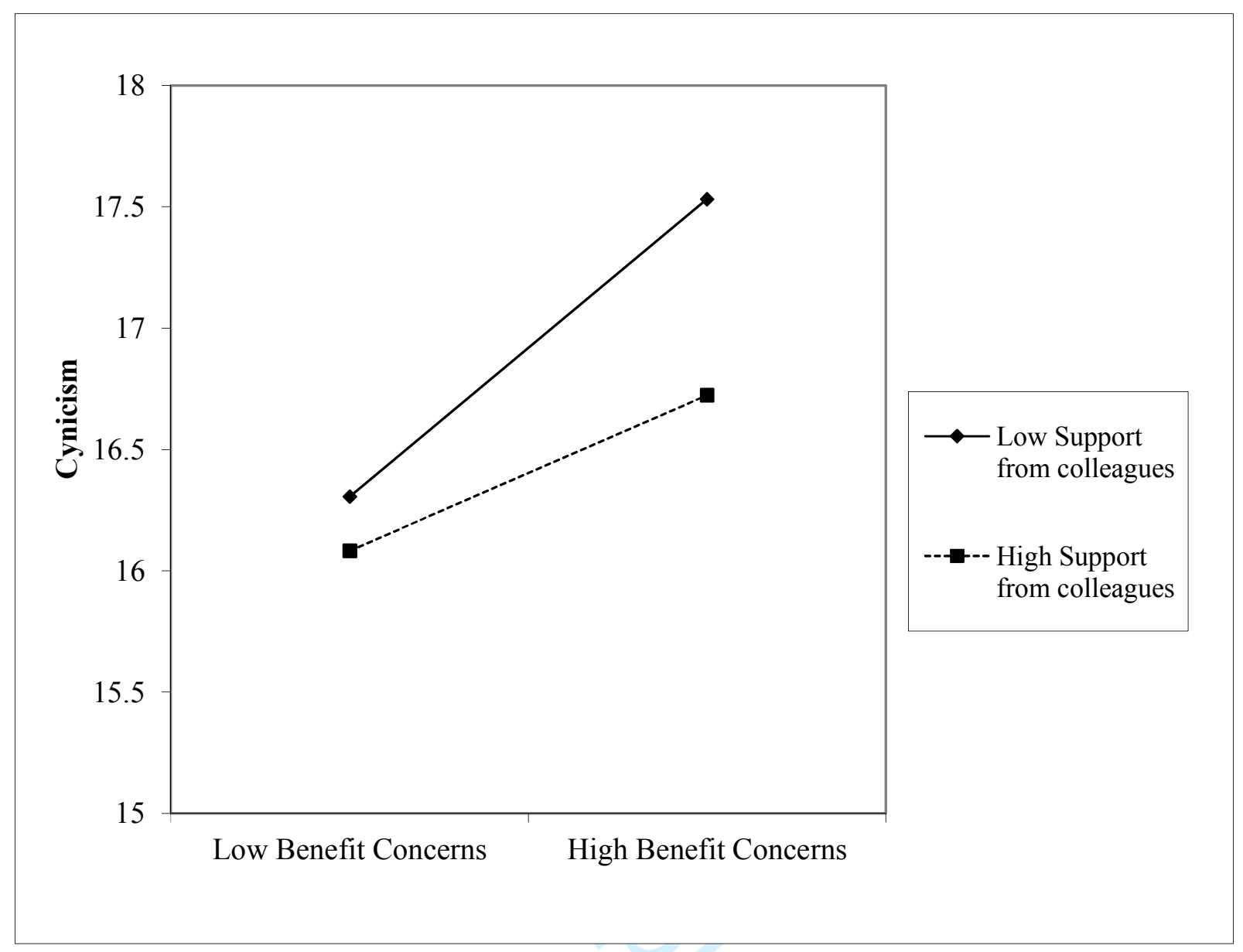

Figure 2. The moderating effect of support from colleagues (SC) in the relationship between benefit concerns (BEN) and Cynicism (CY) 


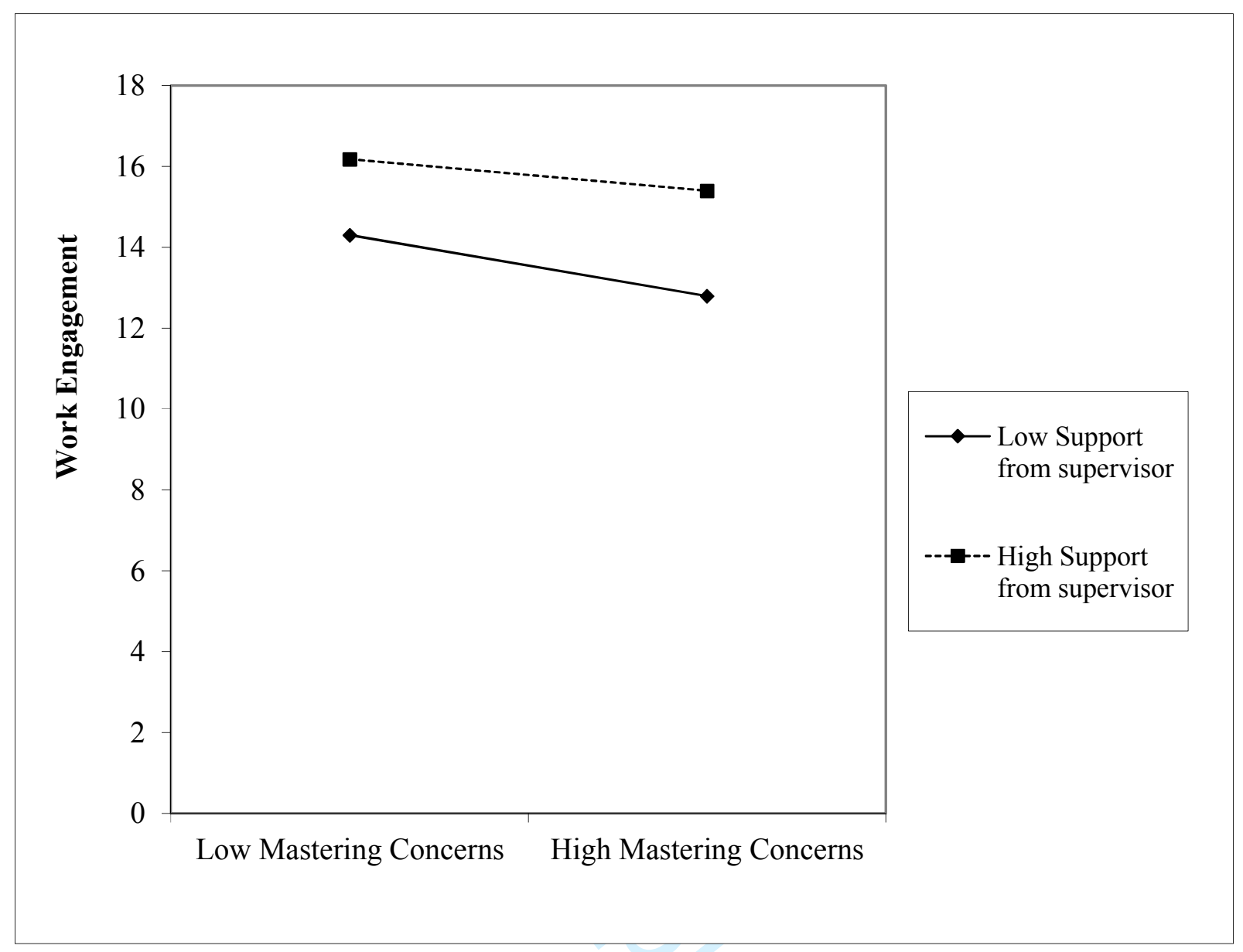

Figure 3. The moderating effect of support from supervisor (SS) in the relationship between mastering concerns (MAST) and work engagement (WE) 
Table 1

$\underline{\text { Means, Standard Deviations and Correlations among study variables }}$

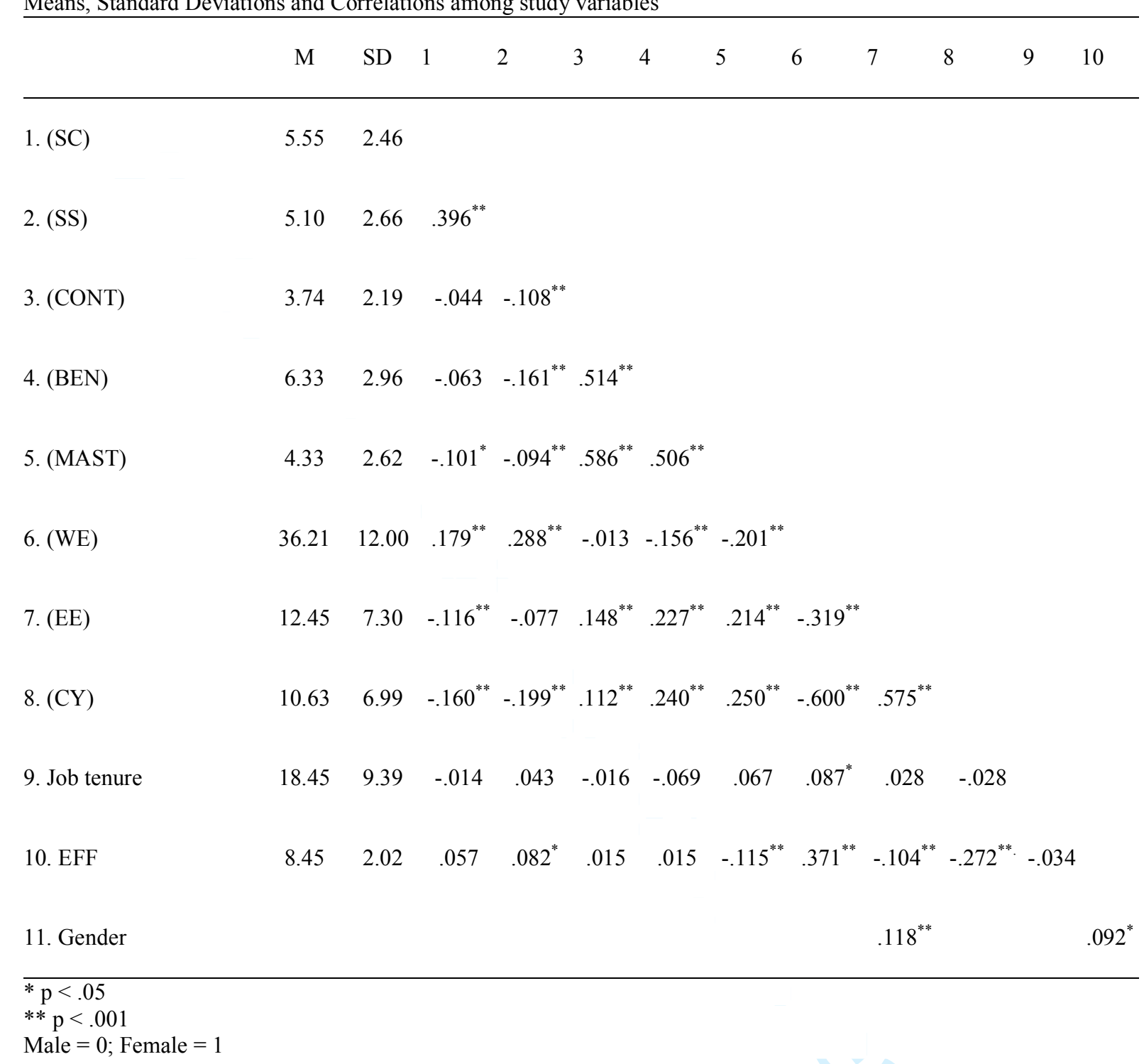


Table 2

Direct and interaction effects between Concerns about change and Support from colleagues

\begin{tabular}{|c|c|c|c|c|c|c|c|c|c|}
\hline & \multicolumn{3}{|c|}{$\begin{array}{c}\mathrm{WE} \\
\left(\mathrm{R}^{2}=.219\right)\end{array}$} & \multicolumn{3}{|c|}{$\begin{array}{c}\mathrm{EE} \\
\left(\mathrm{R}^{2}=.119\right)\end{array}$} & \multicolumn{3}{|c|}{$\begin{array}{c}\mathrm{CY} \\
\left(\mathrm{R}^{2}=.191\right)\end{array}$} \\
\hline & B & $\beta$ & $\mathrm{p}$ & B & $\beta$ & $\mathrm{p}$ & B & $\beta$ & $\mathrm{p}$ \\
\hline Gender & -.01 & -00 & .934 & 2.58 & .159 & .000 & .158 & .010 & .799 \\
\hline Job Tenure & .12 & .09 & .014 & .019 & .024 & .551 & -.041 & -.055 & -160 \\
\hline Self-Efficacy & 2.28 & .38 & .000 & -.472 & -.130 & .002 & -.905 & -.259 & .000 \\
\hline CONT & & & & .026 & .181 & .879 & -.258 & .200 & .114 \\
\hline BEN & & -.09 & .052 & .483 & .087 & .000 & .467 & .168 & .000 \\
\hline MAST & -.55 & -.11 & .011 & .245 & .008 & .099 & .454 & .081 & .001 \\
\hline Step 3: & & & & & & & & & \\
\hline $\mathrm{SC}$ & .57 & .11 & .003 & -.273 & -.093 & .023 & -.308 & -.108 & .006 \\
\hline Step 4: & & & & & & & & & \\
\hline CONT x SC & & & & .078 & .000 & .999 & .074 & -.058 & .242 \\
\hline BEN x SC & .07 & .04 & .297 & -.130 & -.139 & .008 & -.146 & -.162 & .001 \\
\hline MAST x SC & .04 & .02 & .602 & .089 & .074 & .162 & .034 & .031 & .538 \\
\hline
\end{tabular}


Table 3

Direct and interaction effects between Concerns about Mastering change and Supervisor Support in predicting Work Engagement

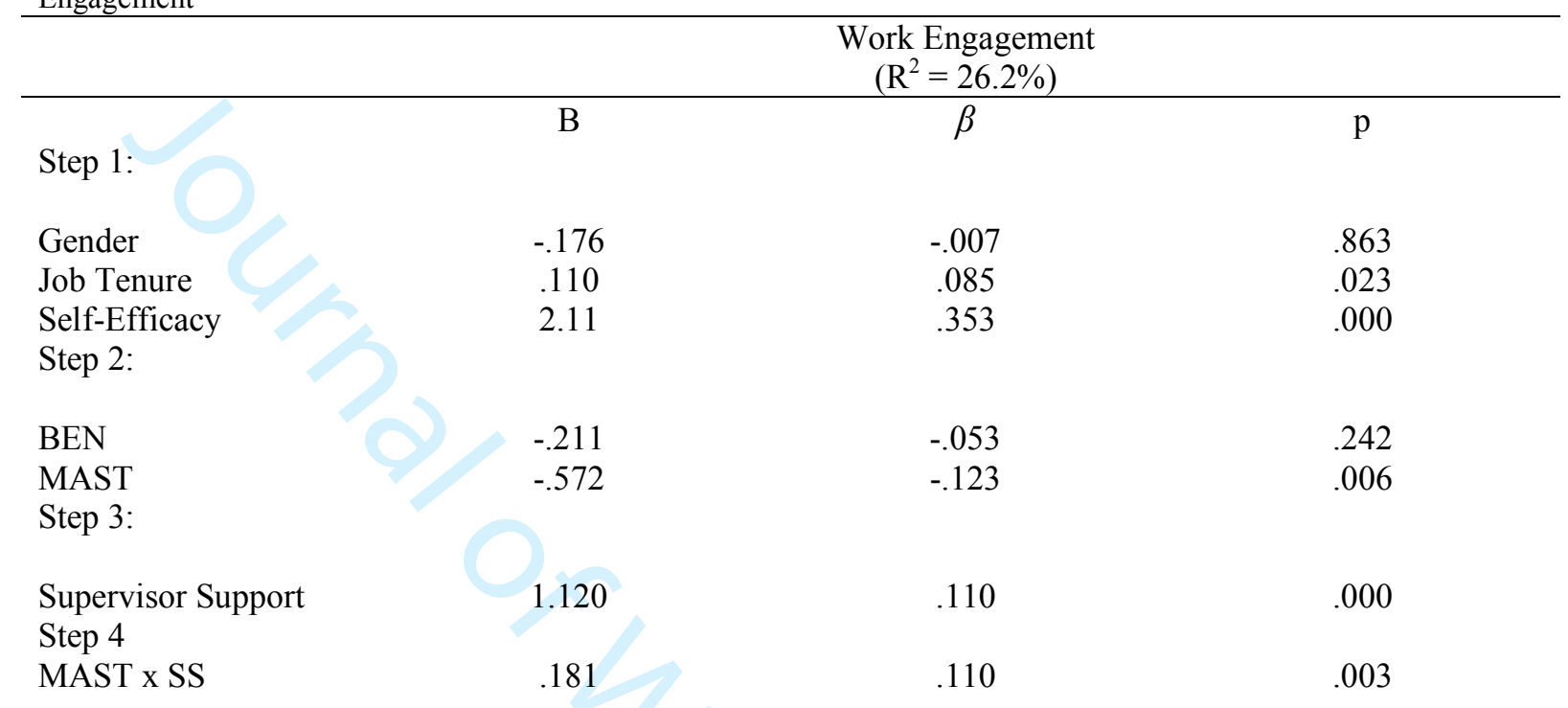

